\title{
Taevasest teenäitajast kommertsmaailma sõnumitoojaks: ingli stereotüübid tarbijareklaamides ${ }^{1}$
}

Reet Hiiemäe

Teesid: Empiirilise uurimuse keskmes on ingli kuvandi rakendamine ja funktsioonid kommertstoodete turunduses. Artikli eesmärk on jälgida inglikuvandi muutumist aja jooksul ning jõuda selgusele, kas reklaamides kasutatud inglikäsitluse põhjal võib teha järeldusi inimeste usundiliste tõekspidamiste ja käibivate väärtushinnangute kohta nii Eestis kui ka laiemalt maailmas. Käsitluse aluseks on umbes 50 ingleid kujutavat reklaami kogu maailmast ning vaatluse all on nii pildi kui video vormis loodud reklaamid, mis on enamjaolt valminud viimase kümne aasta jooksul.

Märksõnad: inglid, mentaliteet, reklaamid, stereotüübid, tänapäevafolkloor, usund, väärtused

\section{Sissejuhatuseks}

Käsitlen oma empiirilises uurimuses ingli kuvandi rakendamist ja funktsioone tarbijareklaamides. ${ }^{2}$ Artikli eesmärk on jälgida inglikuvandi muutumist ajas ning jõuda selgusele, kas reklaamides kasutatud inglikäsitluse põhjal võib teha järeldusi inimeste usundiliste tõekspidamiste ja ajakohaste väärtushinnangute kohta Eestis ja teistes läänelikke majandusmudeleid järgivates riikides. Just nendele piirkondadele on omane ühelt poolt tarbijamentaliteedi võidukäik, teisalt aga viimastel kümnenditel üha populaarsust koguv traditsiooniliste religioonide kaanonitest eemalduv ning usundeid uudsel moel sünteesiv ja üksikindiviidi valikuvabadust rõhutav lähenemine vaimsusele, mille võtab kokku termin new age (eestlaste religioossuse teisenemise kohta 20. sajandi lõpupoolel vt nt Altnurme 2006; Euroopa konteksti kohta laiemalt vt Hanegraaff 1996). Need trendid on jätnud jälje ka uuritavatesse reklaamidesse. Käsitluse aluseks on umbes 50 ingleid kujutavat reklaami kogu maailmast (näiteks Eestis, Saksamaal, Prantsusmaal, Ameerika Ühendriikides, Lõuna-Aafrikas ja Filipiinidel levitatud reklaamid), vaatluse all on enamjaolt viimase kümne aasta jooksul nii 
pildi kui ka video vormis valminud reklaamid. Kuna ammendavat valimit saada oleks tõenäoliselt võimatu, piirdusin ülevaatliku läbilõikevalimiga. Olgu lisatud, et mitmel juhul on tegemist paljudesse keeltesse tõlgitud reklaamidega, mille tootjariiki on raske tuvastada, kuid see ei olegi artikli eesmärk. Huvipakkuvam on tervikpilt, mille puhul võib täheldada suhtelist homogeensust. Inglikujutist ekspluateerivatest toodetest (inglikujukesed, inglimotiividega riided jms) tuleb juttu ainult põgusa taustainfo mahus.

\section{Inglikujutelmade muutumine aja jooksul}

Ingli mõiste (kreeka keeles angelos - saadik, sõnumitooja) on pärit judaismi vanemast kihistusest ja esineb ka piibli varasemates tekstides. Eesti ja laiemalt Euroopa kultuurikonteksti on inglid algselt jõudnudki eelkõige piibli ja ristiusu vahendusel (näiteks jutluste kaudu). Sellelt taustalt lähtuvad ka tänapäevased new-age'ilikud inglikujutelmad, mille kohaselt ingel tegutseb inimese saatja, kaitsja ja juhendajana. Siiski võib nüüdisaegses inglikäsitluses kohata teatavaid laiendusi ja edasiarendusi, näiteks kogetakse inglit lisaks klassikalisele heledais rõivais ja tiibadega ilmumiskujule ka lihtsalt visiooni, tunde või sümbolina (helendav valguspall, valguslaik taevas jms), ettevõtmiste õnnestumiste korral järeldatakse, et need said võimalikuks ingli abiga (näiteks tänu ingli saadetud heale inimesele), kuid ingli seos kristliku religiooniga on teisejärguline või puudub hoopis. Mõnikord võivad inglid olla toeks ka traditsioonilistest kristlikest väärtustest üsna kaugete eesmärkide saavutamisel, näiteks rikastumisel või vastassoole mulje avaldamisel. Seega on inglid new-age'liku käsitluse kohaselt abiks inimese vaimsel täiustumisel, müstiliste kogemusteni jõudmisel, kuid tegutsevad pigem omaette olenditena, mitte rõhutatult kristlike sõnumitoojatena.

Uues testamendis on ingleid kõige enam mainitud Johannese ilmutusraamatus (53 korda), kokku on uues testamendis inglitest juttu umbes 150 korral (vrd Paul 2008). Kaitseingli kujutelm on olnud kristluses tuntud samuti selle algusaegadest saadik - nii katoliiklased kui ka luterlased on traditsiooniliselt uskunud, et igal inimesel on kaitseingel, kes teda abistab ja toetab. Eesti vanemas rahvapärimuses on inglitel oma kindel koht, näiteks on mitmete pärimustekstide järgi igal inimesel oma kaitseingel, kes saadab teda sünnist surmani. Samas pole ingleid käsitlevate rahvajuttude üleskirjutusi siiski kuigi arvukalt (osalt võib ingliteema vähene kajastumine arhiivimaterjalis olla tingitud ka kogumismetoodikast) - folklorist ja rahvausundi uurija Ülo Valk on neid loendanud pisut üle 30 variandi (Valk 1997: 79). Oletatavalt piirduvad Eesti vanemad inglinägemised ja nende kirjeldused eelkõige kitsamate usuringkondadega, 
näiteks mainitakse neid 18. sajandi lõpu ja 19. sajandi hernhuutlaste liikumist kajastavates dokumentides ning külaprohvetite visioonide kirjeldustes (vrd Põldmäe 1935: 135-136; Valk 1999: 229; Petzoldt \& Hiiemäe 2010: 101). Visuaalse toena on rahvapärast inglikujutelma mõjutanud ingli kasutamine arhitektuuris ja kirikukunstis, 20. sajandi algupoolel (esimese Eesti Vabariigi ajal) võis ingleid kohata ka jõulukaartidel (ja pärast Eesti taasiseseisvumist on nad seal taas oma koha leidnud).

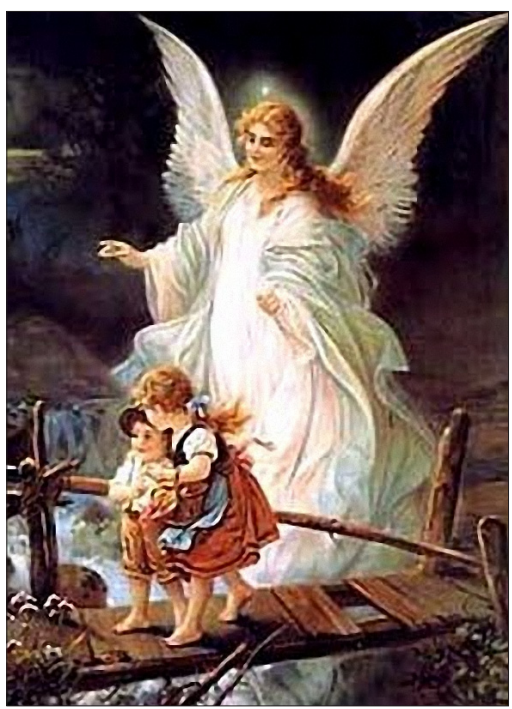

Joonis 1. See katkist silda ületavaid lapsi emalikult kaitsev naisingel on nii mõnelegi meist tuttav vanavanemate kodus seinal rippunud populaarselt pildilt, mille reproduktsioonid levisid laialt 20. sajandi algupoolel.

Seevastu usupuhastaja Martin Luther suhtus inglitesse nagu apostel Paulus, kinnitades, et inglid on küll olemas, aga sel asjaolul ei ole usu jaoks kuigivõrd olulist tähendust, kuna määrav on otsesuhe Jeesus Kristusega (Paul 2008). Tänapäevases kristlikus teoloogias on inglite roll juba üsna väheoluline, nagu märgib ka usuteadlane Toomas Paul (2008: 37): “Tänapäeva vaoshoitud usuteaduses on inglid siiski marginaalsed ning enamik evangeelseid süstemaatilise teoloogia käsiraamatuid ei maini neid üldse, katoliiklased ainult möödaminnes."

Samas on mittekiriklikul tasandil inglite populaarsus viimastel kümnenditel üha kasvanud. Raamatupoodide müügiedu on juba aastaid olulisel määral taganud muude esoteerikaraamatute hulgas ka ingliteema käsitlused - inglite kirjeldused, inglite sõnumid, inglikaardid, eneseabiõpikud inglite toetuse kasutamise kohta (nt Doreen Virtue “Tervendamine inglite abiga”) jms. 2010. aastal 
loodi MTÜ Ingliabi Selts, mis tegeleb inglite abi vahendamisega soovijatele (raha eest). Inglitega samastumise soovile viitavad ka nt eesti interneti esoteerikafoorumid (nt http://tuulepesa.zzz.ee, http://puhastus.planet.ee/forum), kus kõige populaarsemate kasutajanimede seas on inglitega seotud nimed ja kasutajapiltidel kohtab samuti kõige sagedamini ingleid. Kogu Euroopa lõikes on räägitud lausa suurest “inglite tagasipöördumisest” (vrd Böttcher 2006: 73) ja "inglilainest", mis on kestnud alates 20. sajandi viimasest kümnendist tänini, ja väljendub nähtaval kujul eelkõige rikkalikes ingliteemalistes trükiväljaannetes, näitustes ja inglikujutise kasutamises kõikvõimalikel tarbeesemetel alates voodipesust kuni telefonikaardini (vrd Böhm \& Buschmann 2002: 75), rääkimata tootenimedest (nt WC-paber Angelsoft, kondenspiim Angel Milk, Eesti kosmeetikasari Ingli Pai) ja vastavasisulistest reklaamidest. Inglite populaarsuse kasvule on kindlasti kaasa aidanud inimeste huvi suurenemine esoteeriliste õpetuste vastu üldisemalt, mis hakkas Eestis eelkõige tooni andma pärast taasiseseisvumist, kuid on viimastel aastakümnetel täheldatav olnud ka mujal Euroopas ja Põhja-Ameerikas.

Inimeste vaimsuseotsinguid on seega suunanud ja võimendanud oskuslik esoteerikateemaline turundustegevus (nt spetsiaalsed kursused, raamatud ja kaubad), teisalt aga võimaldab just see tuntuse baas mõningate populaarsemate vaimsusega seotud elementide väljumist kitsamatest esoteerika- ja usundiringkondadest ja nende ülevõttu reklaamimaailma. Reklaamiteooriat uurinud Linda Scott märgib oma artiklis reklaamides kasutatavate kujutiste visuaalse retoorika kohta, et ka mitmed näiliselt väheinformatiivsed ja juhuslikud kujutised on tegelikult komplekssed figuratiivsed argumendid, mille valikul reklaami koostaja arvestab vaatajate ühiste kogemustega ja eelteadmistega erinevate mõttevoolude ja -konventsioonide kohta (vrd Scott 1994: 252). Seega on ingli kujutise kasutamine reklaamides käsitletav läbimõeldud visuaalse mõjutamise aktina.

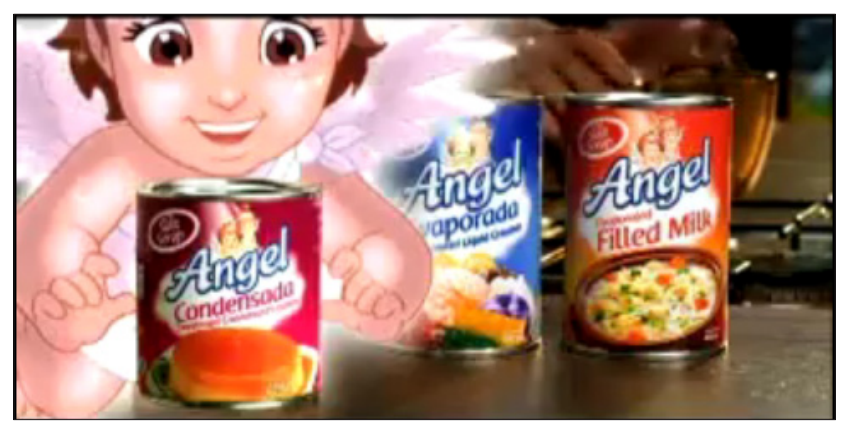

Joonis 2. Kondenspiim Angel Milk. 


\section{Inglid versus ristiusk}

On märkimisväärne, et tänapäeva inimese mõttemaailmas saavad inglid vabalt eksisteerida ka ilma laiema ristiusu kontekstita ja mis kõige tähtsam, sõltumatult jumalast, kelle käskjalaks ja sõnumitoojaks nad algselt olid. Paljud inimesed väidavad sõnaselgelt, et ei usu jumalat ega ühtegi religiooni, küll aga kaitseingleid, märkides näiteks: "Seda ma olen küll kogenud, et kaitseinglid on olemas" või siis jätavad otsad lahtiseks, öeldes: "Ma ei välista, et midagi sellist võib olemas olla" (näited portaalist Delfi Naistekas, 2010). Arutelusid kaitseinglite olemasolust ja väljendusvormidest leidub mitte ainuüksi spetsiifilistes esoteerikafoorumites, vaid ka näiteks pere- ja naistefoorumites (vt nt Buduaar). Ka populaarses ajaviiteportaalis Delfi Naistekas tõstatati alles möödunud talvel (12. veebruar 2011) kaitseingli-teema ja kutsuti üles lugejaid jagama oma arvamust ja kogemusi seoses kaitseinglitega (vt Delfi Naistekas) artiklile saabus 115 kommentaari, neist enamikus peeti kaitseinglite olemasolu võimalikuks või mingi isikliku kogemuse kaudu tõestatuks. Teoloog Toomas Paul märgib selliste tendentside kohta mõningase kibestumisega: "Postkristliku Euroopa ateist on vaktsineeritud ja immuunne traditsioonilise kristluse suhtes. Ta on antiklerikaal, kes kardab kirikut ja Kristust nagu kuradit, aga on aldis uskuma aurasid ja avataarasid, ingleid ja indigolapsi" (Paul 2008: 37). Samas tundub kaitseingli teema lähedane ka kristliku taustaga inimestele (vrd Potter 2001; 2002). Sellisel raskuskeskme muutumisel on mitmeid põhjuseid. Ingel pole tavainimese silmis nii raskepärane kui ristiusu klassikaline teoloogia tervikuna. Samuti ei pea inimene ingleid eraldi käsitledes enda jaoks selgeks mõtlema keerulisi ja kohati tõrget tekitavaid süü ja patu teemasid. Pealegi on igal - ka ristiusukaugel - inimesel olemas arusaam sellest, milline üks ingel võiks välja näha. Sellele on muuhulgas kaasa aidanud eriti jõuluajal müüdavad kommertslikud kaubaartiklid (nt täidavad vilkuvad, värvimuutvad, helendavad jms inglikujukesed märkimisväärse osa jõulueelsetest postimüügikataloogidest, samuti kohtab ingleid kaubanduskeskuste jõulukujunduses, jõulukaartidel, jõulukinkide pakenditel).

Joonis 3. Värvimuutvad ja helendavad inglikujukesed postimüügikataloogist Select (2010).

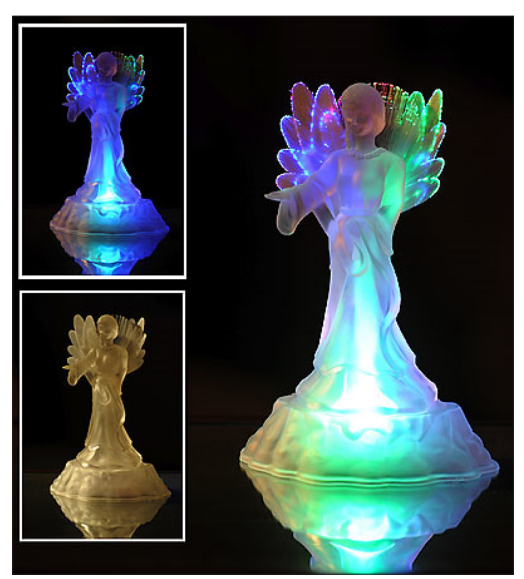


Ingliuskumusi populariseerivad ka mittekanoonilist kristlust esindavad põnevana mõjuvate alternatiivsete usundiliste vaadetega inimesed ja raamatud. Näiteks ilmus 2010. aastal terve raamat Inglite tervendav vägi (koostaja Aive Antsov), mis sisaldab Eesti tervendajate ja selgeltnägijate, aga ka tavainimeste kommentaare nende suhete kohta inglitega. 2011. aastal ilmus samalt koostajalt teinegi raamat: Inglid ja planeet. Viimastel aastatel avalikkuses populaarseks muutunud noor Eesti selgeltnägija Nastja sedastab seltskonnaajakirjas Kroonika: "Ingel on olemas igal inimesel, mõnel on neid rohkem või mõnel on need tugevamad - nagu kangelased" (Nastja, 26. okt 2006). Oma suhetest inglitega on ajakirjanduse kaudu teada andnud näiteks näitleja Kleer Maibaum-Vihmar (Aavik 2010) ja laulja Pirjo Levandi (publik.delfi.ee 2007). Näib, et just 2000. aastate teisest poolest peale on ingliteema kajastumine ajakirjanduslikes persoonilugudes sagenenud.

\section{Inglite kujutamine reklaamis}

Üldisele inglibuumile on operatiivselt reageerinud ka reklaamitootjad - ingel leiab kommertsmaailma sõnumitoojana reklaamides järjest laiemalt kasutust. Põhjuseid, miks inglist on saanud üks reklaamide meelisfiguure, on mitmeid:

1. Ingel on kergesti äratuntav ja pilkupüüdev - avalikkuse teadvuses kindlalt ankurdunud kuvand, mis ei vaja mingit täiendavat lahtiseletamist (vrd ka Böttcher 2006: 298).

2. Ingli kuvand on positiivne ja turvalisust sisendav ega tekita komplitseeritud negatiivseid kõrvalassotsiatsioone - seetõttu on ingel nt jõuludekoratsioonides märkimisväärselt populaarsem kui Jeesus või muud algselt tunduvalt kandvamate rollidega piiblitegelased.

3. Osalt eelnimetatud põhjustel on inglit kerge näidata lõbusas või karikeeritud võtmes - on ju tarbija naermaajamine ja selle kaudu tema vastuvõtlikkuse suurendamine üks tuntud reklaamivõtteid. Pealegi on inglite puhul tunduvalt väiksem oht riskida usuringkondade ägeda meelepahaga, mis on kaasnenud näiteks Allahi või Jeesuse karikeeritud kujutamisega. Inglitel puudub n-ö autoriõigus, kuna need on esindatud erinevates religioonides.

Efektse ja pilkupüüdva välimuse tõttu on kaitseinglit kasutatud ka mittekommertslikes teavituskampaaniates (vrd Hein 2011). 


\section{Reklaamiinglite tüübid}

Reklaamis kujutatud ingleid on erinevaid, kuid kasutatud inglitüüpide arv on siiski üsna piiratud. Järgnevas pakun vaadeldud valimi põhjal välja lihtsa kolmetise klassifikatsiooni.

1. Otseselt inimlike pahedega ingel. Kaitseingli funktsioon puudub; põhifunktsioon on veenda tarbijat, et toode on nii hea, et isegi ingel ei suuda sellele vastu panna. Eesmärgiks on ingli kuvandi kasutamise kaudu legitimeerida ostu- ja tarbimishullust ning hedonistlikku eluviisi, nagu näiteks reklaamis, milles ilmuvad West sigarette pahviv mees- ja naisingel (vt joonis 4 ja 5 ). Paheliste inglite puhul on aimatav assotsiatsioon langenud inglitega; mõtteline

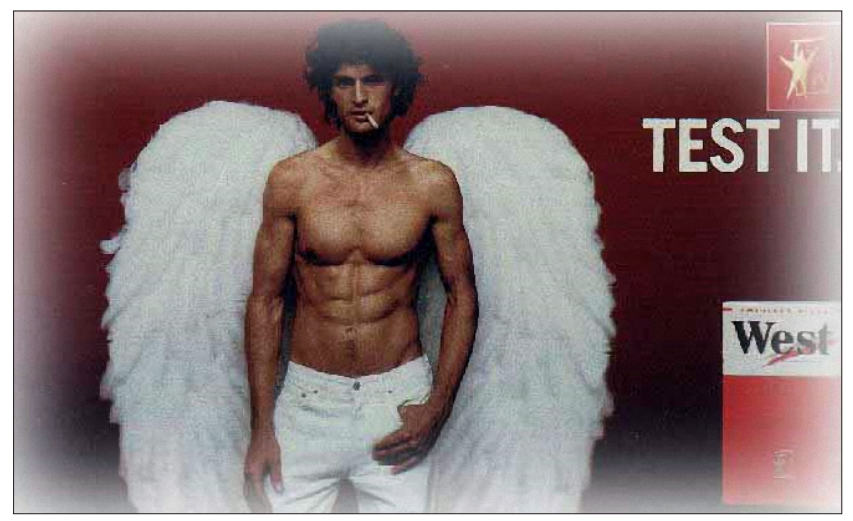

Joonis 4. Paheline meesingel sigaretitootja West kangema sigaretimargi reklaamis.

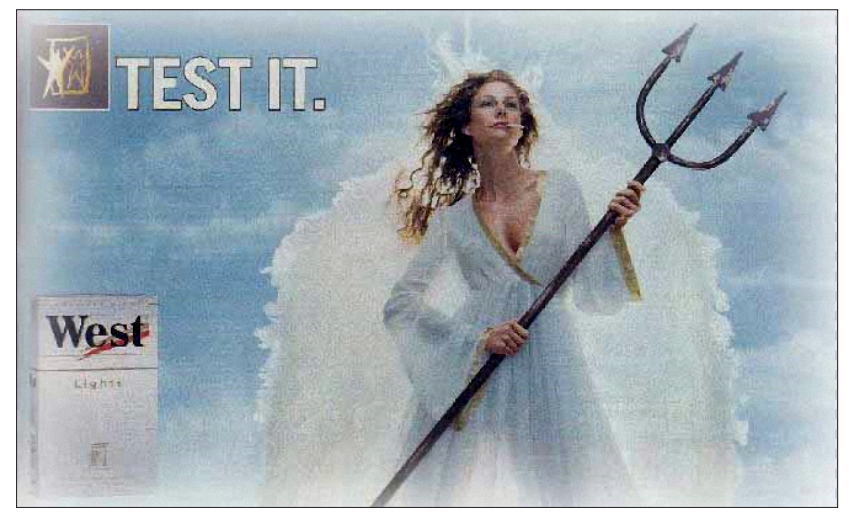

Joonis 5. Kolmhargiga naisingel sigaretitootja West light-tüüpi sigaretimargi reklaamis. 
taustaseos taevaste olendite meelelisusega on tajutav paralleelina piibli kirjakohaga, mis kirjeldab, kuidas "Jumala pojad nägid, et inimeste tütred olid ilusad ja nad võtsid enestele naisi kõigist neist, keda nad välja valisid” (1 Mo 6: 1-3). Reklaamiinglitel puuduvad loomulikult igasugused teoloogilised kiusatuse ja pattulangemise allegooriad - need inglid on valmis vähimate süümepiinadeta kõikidele kiusatustele järele andma, jäädes sealjuures kadestamisväärselt nooreks, terveks ja seksikaks.

2. Traditsiooniline kaitseingel äraspidises võtmes. Nendes reklaamides on inglitel küll nii-öelda klassikalised atribuudid, nagu tiivad ja hele rüü, kuid reklaamid ise on enamasti üles ehitatud inglite negatiivsetele, kuid inimlikuks peetavatele omadustele - näiteks laisk kaitseingel (ingel saab endale laiskust või lohakust lubada, kuna Ergo kindlustus, Mercedes Benz auto vms kaitseb juba inimest niigi) või valelik ja torisev kaitseingel (näiteks Ergo kindlustuse reklaamis valetab tualetis ajalehte lugev ingel, et tal pole aega, või toriseb piljardit mängiv ingel, et tal on tööpäev läbi, mistõttu ta ei pea kaitsmisega tegelema, seevastu kindlustus kaitseb inimest alati). Huumorivõtmes kujutatud kaitseingel võib olla ülekaaluline või kiilaspäine. Saksa kindlustusfirma Provinzial, mis kasutab stiliseeritud inglit ka oma logona (http://www.provinzial. com/web/html/privat/versicherungen/index.html), on kasutanud kaitseingli kuvandi baasil tehtud šokireklaami - kergemeelne kaitseingel jõuab kohale alles siis, kui liiklusõnnetus on juba toimunud. Reklaam seab Provinziali kaitsevõime ingli omast kõrgemale, kinnitades, et ka kaitseinglid puhkavad mõnikord, aga kindlustus mitte kunagi.

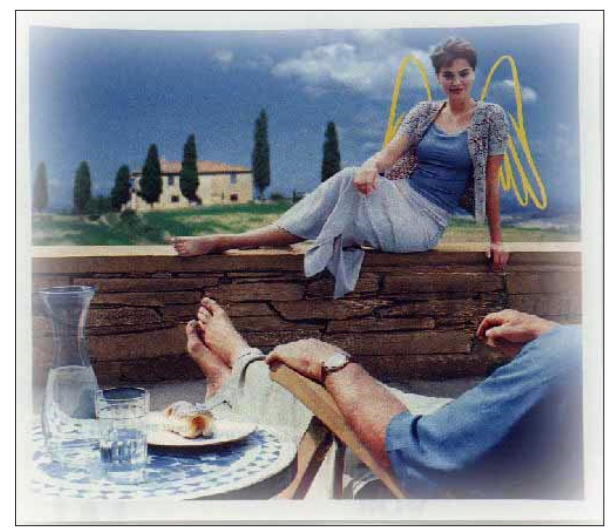

Joonis 6. Puhkepausi tegev ingel kindlustusfirma Provinzial reklaamis.

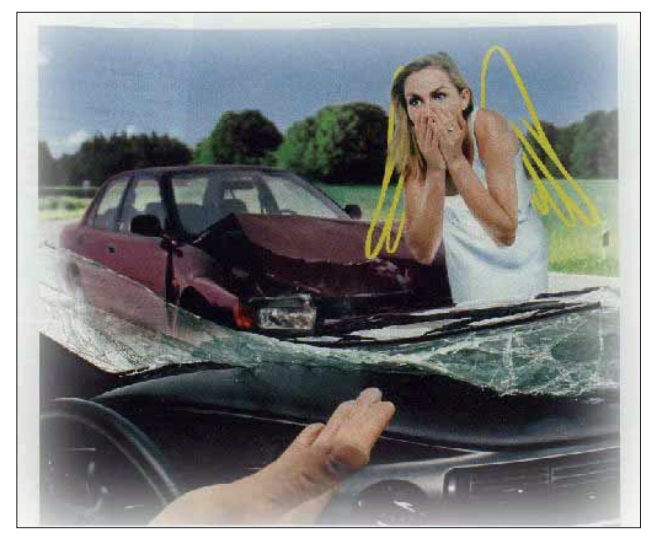

Joonis 7. "Ka kaitseinglid võtavad mõnikord aja maha. Provinzial on teie jaoks ööpäevaringselt kohal." Kindlustusfirma Provinzial reklaam. 
3. Traditsiooniline kaitseingel kaitsvas funktsioonis - need reklaamid ei rõhu mitte efektsusele, vaid armsusele, kujutades näiteks kohalelendavaid lapsingleid, kes aitavad tühja kütusepaagiga auto koos selles sõitva isa ja lapsega Olerexi tanklasse. Inglikujutist logona kasutava Saksa reklaamifirma Engel-Werbung puhul jääb aga otsene seos inglitega täpsemalt lahti seletamata, mainitakse ainult, et firmas pakutakse taevalikku teenindust, seega loodetakse siin klassikalise inglistereotüübi abil luua firmale lihtsalt positiivset kuvandit.

\section{Inglite sugu religioonis ja reklaamis}

Usuteadlane Toomas Paul (2008: 39) märgib inglite soo kohta järgmist: "Kuigi Matteuse evangeeliumis (22:30) öeldakse, et inglitel ei ole sugu - "ülestõusmisel ju ei võeta naist ega minda mehele, vaid ollakse nagu inglid taevas", on muistsete epifaaniate inglid mehed resp. noored mehed, kelle ilmumine tingib üldjuhul esmase reaktsioonina kabuhirmu - nii jõuluööl karjastel kui ka Jeesuse hauale läinud naistel" (vt Lk 2:9j; Mt 28:4.8; Mk 16:58; Lk 24:5). Ka kujutavas kunstis on inglid algselt olnud enamasti mehed, ja neid on kujutatud ilma tiibadeta. Alles alates 4. sajandist lisanduvad vähehaaval inglitele tiivad (Böhm \& Buschmann 2000: 78), gootikas (12.-13. sajand) ilmusid juba ka antiikajast inspireeritud alasti või poolalasti lapsinglid, naissoost inglid saabusid aga alles renessansiajal (alates 14. sajandist).

Tänapäevastes reklaamides leidub ingleid nii täiskasvanud mehe, noore naise kui ka lapse kujul. Pead ümbritsev nimbus on üldjuhul kadunud või siis kaob reklaami jooksul (säilinud on see siiski nt Angel Milk kondenspiima reklaamivatel lapsinglitel). Täiskasvanud inglite riietus on pigem napp, seksikas ja moodne, tihti rakendataksegi neid just pesureklaamides, nt Victoria's Secret hooajakampaaniad. Ainult lapsinglid käivad veel klassikalistes pikkades heledates särkides või poolpaljalt (nt Mercedes Benzi autoreklaami lapsinglid). Lapsinglid kalduvad reklaamides ilmuma paarikaupa või rühmana, meesinglid ilmuvad rühmana või üksi, naisinglid valdavalt üksi.

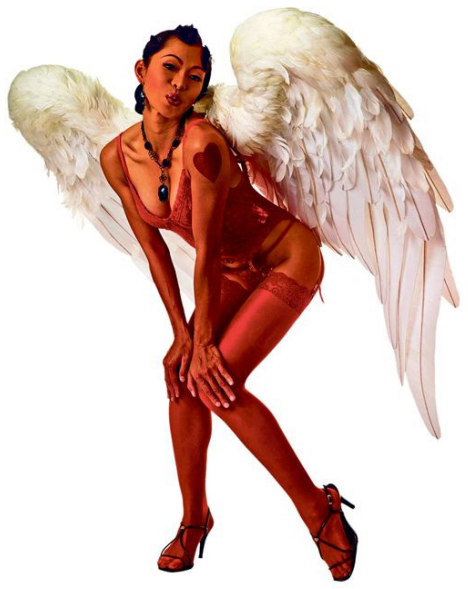

Joonis 8. Prostituudilik ingel pesu reklaamimas. 


\section{Reklaamiingli deemonlikud jooned}

Reklaamide ingel ei ole Jumala sõnumi tooja ega teenäitaja, vaid klassikalises mõistes pigem pattu ahvatleja. Kui piibli jm kristlikus kontekstis olid inglid abilised, kes aitasid inimesel kiusatusele vastu panna, siis tänapäeva inglireklaamide põhiline sõnum on vastupidine: kiusatusele ei ole võimalik vastu panna, pole mõtet üritadagi, sest seda ei suuda inglidki. Ingel tegutseb autonoomselt ja jumalast sõltumatult, jumalat võidakse mainida vaid muuseas ja pigem muigamisi (nt nimetab ingel teda bossiks, ülemuseks). Jumala asemele on mõtteliselt asunud tarbimismaailm, mille sõnumeid ingel inimestele vahendab. Paralleele on kaasaegse konsumerismi ja klassikalise religiooni vahele tõmmatud mujalgi: "Nii nagu religioon, tõotavad ka reklaam ja konsumerism meile õnnerikast elu. [---] Religioosne kapitalism on üks meie ajastu märke" (Glauben+Kaufen). Teisal on suurfirmade visionääridest juhte nimetatud moodsateks evangelistideks (vrd Stepken 2007). Reklaam näib seega soovivat võtta üle religiooni rolli - panna inimene uskuma ja järgima reklaami ilma küsimusi esitamata.

Näiteks West sigaretireklaami noor palja ülakehaga brünett meesingel kehastab vaba ja vabameelset, sportlikku, eksootilis-erootilist meest, kelle välimus võiks tekitada pigem assotsiatsiooni kuradiga, kui talle poleks külge poogitud valgeid tiibu. Ilmselgelt on reklaami paheline alltoon taotluslik (vrd ka Böttcher 2006: 80). Igal suitsupakil olev hoiatav teade, mis tuletab meelde, et suitsetamine võib tappa, paisatakse reklaamis kujutatava meelelisusest ja tervisest pakatava inglifiguuriga põrmu. Tõmmusid ja mehelikku seksuaalsust rõhutavaid noori mehi on reklaamiinglite seas üldse võrdlemisi palju (vt ka nt Lancia autoreklaamid).

Reklaamid sisendavad inimestele ka samastumissoovi, väites et teatud asju omades ja kasutades avaneb inimesele justkui kiirtee taevasse, näiteks muudab reklaamitav kosmeetika naised jumalikuks (Nina Ricci parfüüm, mida reklaamib valgesse rõivastatud noor ahvatlev ingel tekstiga: kaunis armastuse ja rahu ingel) või lausa jumalannadeks (Gillette Venus raseerija), spaa-protseduurid on taevalikud või paradiislikud. Isegi vaipu saab osta vaibaparadiisist või diivaneid diivaniparadiisist (nendele vastukaaluks on ostupõrgud - vahel ei kardeta nimetada "pattu" ka õige nimega).

Seega on algne piiblisõnum pea peale pööratud: inimesi püütakse veenda, et paradiis peitub ajalikus ja maises, või lausa n-ö pahedes (alkoholi nautiv ingel, sigarette suitsetav ingel, joonised 9 ja 10). Ingliga samale tasemele või paradiisi jõudmiseks pole vaja pikka ja vaevarikast meeleparandust ja enda muutmist, piisab toote ostmisest. Täiskasvanud ingel on tarbimisele orienteeritud inimideaali kehastus: tal on võim, puuduvad mured (ta on alati noor ja terve ning surematu), ta näeb hea välja ja võib sealjuures tarbida kõike - ka ebatervislikku, sõltuvust tekitavat ja kallist, nagu näiteks Saksa alkoholirek- 


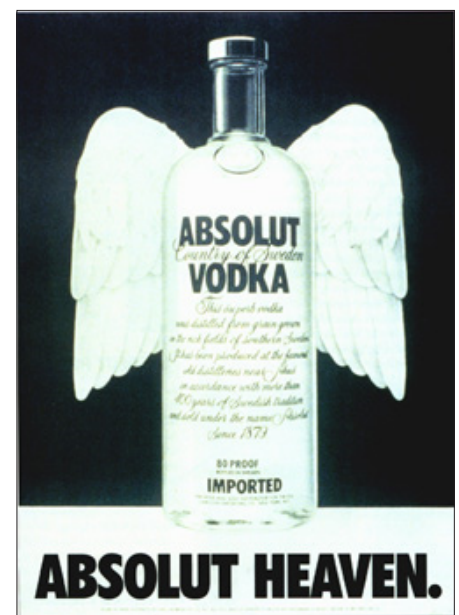

Joonis 9. Absoluut vodka reklaam omistab alkoholile taevalikud dimensioonid: "Absolut vodka. Absolut heaven."

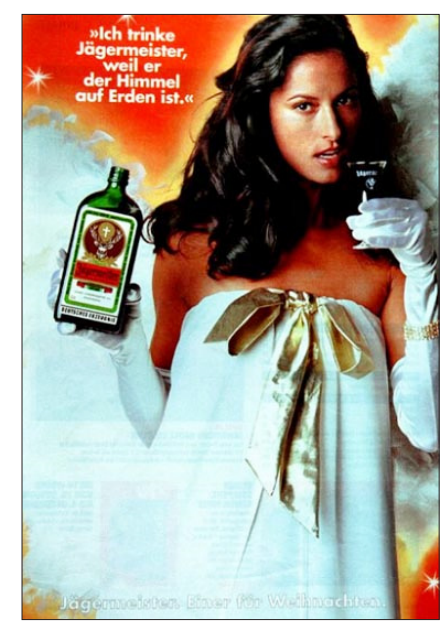

Joonis 10. Jägermeistri likööri reklaamiv ingel ütleb: "Mina joon Jägermeistrit, kuna see on maapealne taevas." All on täiendav tekst. Jägermeister. See õige jõuludeks.

laami noor ahvatlev naisingel, kes hoiab ühes käes Jägermeistri pudelit, teises joogiklaasi ja lausub: "Mina joon Jägermeistrit, kuna see on maapealne taevas." Piiblistseene ingleid kujutavates reklaamides üldjuhul ei esitata, ei leidu isegi allusioone neile (ainult üks reklaam mängib siiski parodeerivas võtmes läbi ka Jeesuse sünniloo). Üksikutel kordadel üritatakse reklaamile lisada sügavmõttelisust klassikuid tsiteerides, näiteks on ühes Lancia autoreklaamis toodud lau-

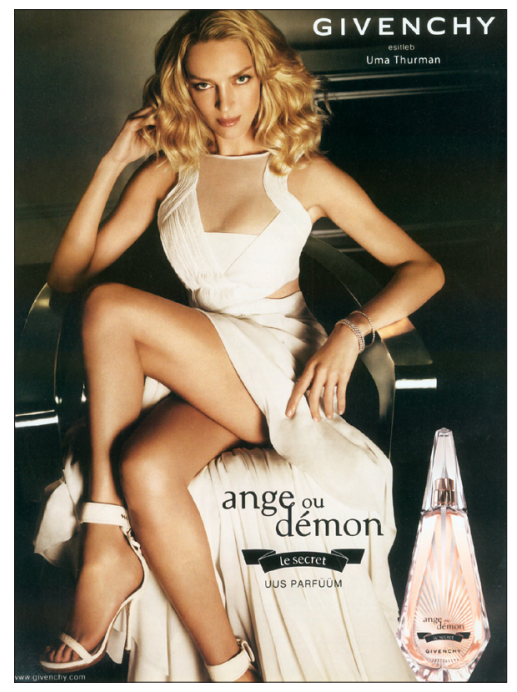

Joonis 11. Dilemma ingel või deemon Givenchy parfü̈mireklaamis. se Shakespeare'i komöödiast "Asjatu armuvaev", kuid selle sisu on vastavalt reklaami eesmärkidele ümber tõlgendatud, reklaami pilgupüüdjaks on brüneti tumedates riietes ja tumedate tiibadega naisingli ja samuti tumedaverelise noore mehe armukohtumine, mille käigus inglil tiivad seljast kukuvad.

Reklaamiingel on mõnikord sedavõrd äravahetamiseni sarnane kuradiga, et vaatajal kipub segi minema, kumb ta lõpuks õieti on. Nii kannab Givenchy reklaamitav parfüüm nime "Ange ou démon" (ingel või deemon) ja sama küsimusega maadleb reklaamvideos ingelliku välimusega naine, kes näeb peeglis enda peegelpildina hoopis deemonit (joonis 11). Samuti ilmub Nina Ricci parfüümireklaami ühel hetkel võrgutav naiskurat, kelle 


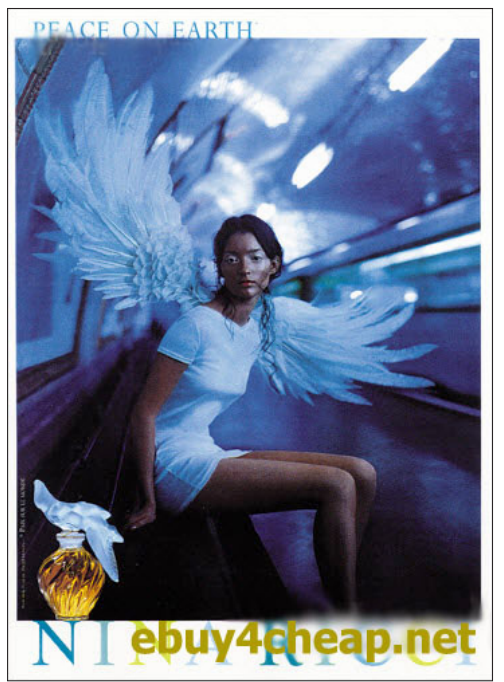

Joonis 12. Nina Ricci jõuluaegne parfü̈mireklaam "Rahu maa peal".

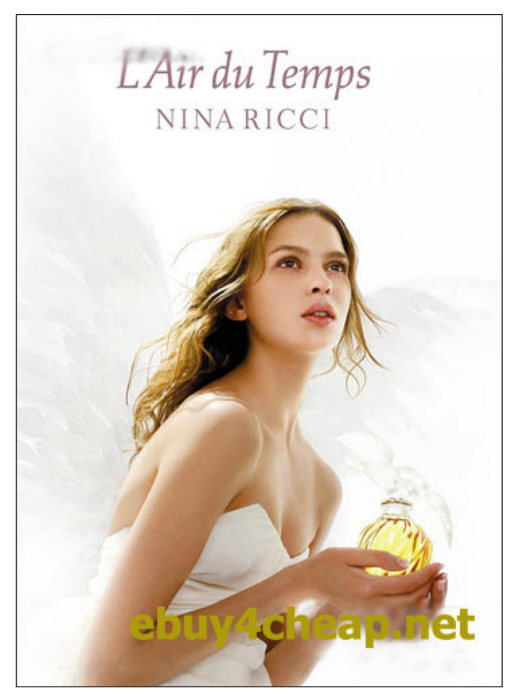

Joonis 13. Nina Ricci parfü̈mireklaam naisingliga.

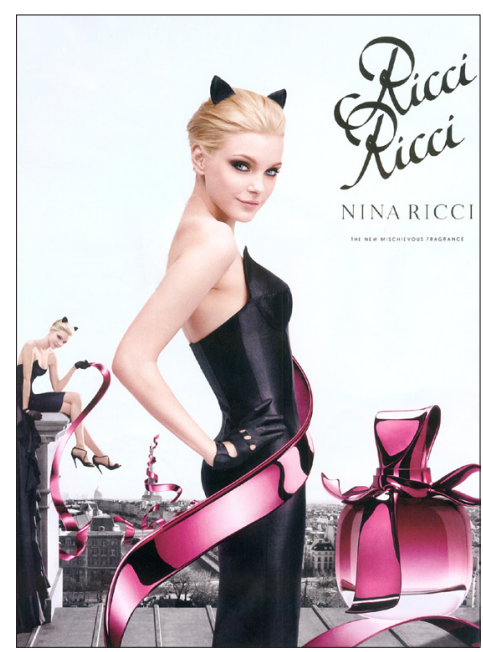

Joonis 14. Nina Ricci parfü̈̈mireklaam naiskuradiga. Isegi kleidimood on sama nagu joonisel 13 kujutatud inglil, vaid must värvus ja väiksed sarvekühmud annavad vihje deemonlikule sfäärile. puhul isegi kleidimood sarnaneb sama firma varasemas reklaamis kasutatava naisingli omaga (joonised 12-14). Jääb vaid kommenteerida, et keskajal oleks selline mentaalne kahestumine tõenäoliselt kaasa toonud mõne kainestava eksortsismiriituse, tänapäeval aga toimib see pilkupüüdva ja teadlikult piire hägustava reklaamitrikina. Seega reklaamiinglid langevad ja eksivad (nt meesteparfüümi Lynx Excite reklaam), muutuvad inimesteks (nt Coca-Cola reklaam) ning mõned lausa deemoniteks ja kuraditeks või on nendest muidu vaid suurivaevu eristatavad. Samas aga reklaamides, mille tegelasteks on kuradid, selline ambivalentsus puudub, kuradid jäävad ausalt ja üheseltmõistetavalt kuraditeks, nagu näiteks kartulikrõpsutootja Lay's reklaamis krõpse sööv kurat (joonis 15). 


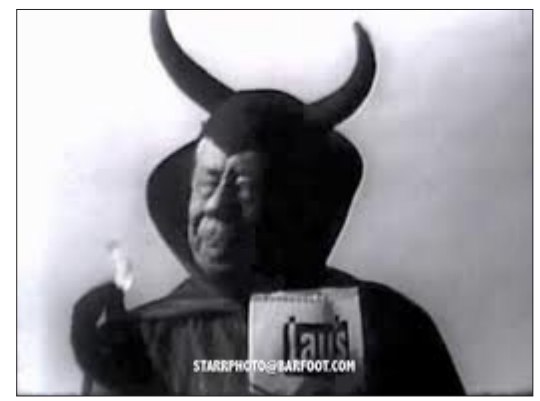

Joonis 15. Lay's krõpse reklaamiv kurat.

\section{Lõpetuseks}

Kirjutises näitasin, et ingleid kujutavate reklaamide üks põhifunktsioone on uinutada inimese turvalisuse ja kaitstuse soovile, aga ka humoorikale efektile välja mängides tema valvsus ja vastupanuvõime ning ahvatleda teda tarbima. Ühtlasi lisab ingli kuvandi kasutamine reklaamile atraktiivsust sellega, et see täidab inimesele loomuomast ihalust salapära ja müstilisuse järele. Olles kord ahvatlevalt sensuaalsed, kord pilkupüüdvalt armsad, kord igatsusttekitavalt ebamaised, peavad reklaamiinglid looma toote ja inimese vahel emotsionaalse silla, mis mõjutab tarbija ostuotsuseid. Selles osas ei erine Eesti reklaamid valimi ülejäänud reklaamidest: ei leidunud ühtegi episoodi, mille poolest Eesti reklaamid oleksid võrreldes ülejäänutega täiesti unikaalsed.

Samas ei julgeks ma erinevalt mitmetest autoritest (vrd nt Böhm \& Buschmann 2002: 77) nimetada inglite jõulist pealetungi reklaamimaailmas tingimata üheseks märgiks inimeste sekulariseerumisest ja religiooni trivialiseerumisest. Reklaamis tulevad selle lihtsustatusest ja skemaatilisusest tingitult selgelt esile nüüdismaailma unistused: ka tänapäeval jätkuvad elu mõtte ning oma identiteedi ja kuuluvuse otsingud, kuid teenäitajateks on siin sageli asjademaailma ersatsreligiooni inglid; samuti ei ole kuhugi kadunud inimeste igatsus üleloomuliku kaitsja ja päästja järele, kes vastutusest vabastaks ja imeväel elu õigele rajale suunaks. Ja peaasi, et see hea elu algaks kohe, mitte alles võib-olla kunagi kauges tulevikus pärast surma.

\section{Kommentaarid}

1 Artikkel on valminud sihtfinantseeritava teadusteema "Folkloori narratiivsed aspektid. Võim, isiksus ja globaliseerumine” raames (SF0030181s8). 
${ }^{2}$ Artikli aluseks on otseselt turunduslikel kaalutlustel loodud reklaamid, seega jäävad antud käsitlusest välja näiteks sotsiaalreklaamid.

\section{Kirjandus}

Aavik, Kadi 2010. Kleer Maibaum - hingates kõikvõimsaks. Naised 6.04.2007 (http:// naistemaailm.ee/?id=10563 - 2. juuli 2012).

Altnurme, Lea 2006. Kristlusest oma usuni. Uurimus muutustest eestlaste religioossuses 20. saj. II poolel. Tartu: Tartu Ülikooli Kirjastus.

Antsov, Aive (koost) 2010. Inglite tervendav vägi. Tallinn: Vaba Maa.

Antsov, Aive (koost) 2011. Inglid ja planeet. Tallinn: Vaba Maa.

Böhm, Uwe \& Buschmann, Gerd 2002. Religion in der Werbung und Werbung als Religion. Teil 3: Von Engeln und Teufeln in den Medien. Medienimpulse. Beiträge zur Medienpädagogik. Heft 39. Wien, lk 75-80 (http://www.mediamanual.at/mediamanual/ themen/pdf/werbung/39_Boehm_Buschmann.pdf - 12. jaanuar 2012).

Böttcher, Carina 2006. Engel in Literatur, Film und Werbung. Magisterarbeit zur Erlangung des Grades Magistra Artium der Philosophischen Fakultät der Heinrich-Heine-Universität Düsseldorf (http://www.mythos-magazin.de/mythosforschung/cb_engel. pdf - 12. jaanuar 2012).

Buduaar = Kes teab midagi inglitest? Buduaar.ee (http://buduaar.ee/Foorum/Forum/ topic/208037\&lk=2 - 26. aprill 2012).

Delfi Naistekas = Kui ingel valvab meie üle. Delfi Naistekas (http://naistekas.delfi.ee/ horoskoop/salateadus/kui-ingel-valvab-meie-ule.d?id=40130222 - 26. aprill 2012).

Glauben + Kaufen = Religiöse elemente in der Werbung. Glauben + Kaufen (http://www . glauben-und-kaufen.de/ - 26. aprill 2012).

Hanegraaff, Wouter J. 1996. New Age Religion and Western Culture: Esotericism in the Mirror of Secular Thought. Leiden, New York, Köln: Brill.

Hein, Inna-Katrin. "Kaitseingel" hoiatab autojuhte kiiruse ületamise eest. Postimees Elu24 (http://www.elu24.ee/?id=262308 - 27. aprill 2012).

Nastja 2009. Selgeltnägija Nastja: igal inimesel on ingel! Kroonika, 26. oktoober (http:// www.kroonika.ee/index.php?id=32828 -26 . aprill 2012).

Paul, Toomas 2008. Inglid läbi aja. Horisont 6, lk 36-41 (http://www.horisont.ee/node/744 - 26. aprill 2012).

Petzoldt, Leander \& Hiiemäe, Reet 2010. Väike deemonite ja vaimolendite leksikon. Tartu: EKM folkloristika osakond ja Eesti Folkloori Instituut.

Potter, Terje 2001. Tänapäeva kogemusjutud inglitest. Situatsioonianalü̈̈s ja kristlikud lähtekohad. Bakalaureusetöö. Tartu: Tartu Ülikool. 
Potter, Terje 2002. "Räägi minuga inglitest." Raadiosaade ja inglijuttude situatsioonianalüüs. Lemmeleht. Pro Folkloristica IX. Tartu: Eesti Kirjandusmuuseum, lk 168-180 (http://www.folklore.ee/era/nt/PF9/Potter.htm - 26. aprill 2012).

Publik.delfi.ee 2007 = Pirjo Levandi leidis inglid. 19.10.2007 (http://publik.delfi.ee/news/ inimesed/pirjo-levandi-leidis-inglid.d?id=17202238 - 2. juuli 2012).

Põldmäe, Rudolf 1935. Taevakäijad. Kaleviste mailt. Õpetatud Eesti Seltsi kirjad, III. Tartu: Õpetatud Eesti Selts, lk 123-176.

Scott, Linda M. 1994. Images in Advertising. The need for a Theory of Visual Rhetoric. The Journal of Consumer Research 21 (2) sept 1994, lk 252-273.

Stepken, Guido 2007. Marketingstrategien in dynamischen Märkten und die Vorhersagbarkeit von Bestsellern. OPPapers.com Free Essays and Research Papers (http://www. little-idiot.de/teambuilding/MarketingVorhersagbarkeitBestsellern.pdf - 26. aprill 2012).

Valk, Ülo 1999. Angels in Estonian Folk Religion. Studies in Folklore and Popular Religion 2. Tartu: Department of Estonian and Comparative Folklore, University of Tartu, lk 219-238.

Valk, Ülo 2007. Inglid eesti rahvausundis. Kõiva, Mare (toim). Artikleid usundi- ja kombeloost. Sator 6. Tartu: EKM Teaduskirjastus, lk 77-96 (http://www.folklore.ee/rl/ pubte/ee/sator/sator6/4ylovalk.pdf - 26. aprill 2012).

\section{Viiteid kasutatud reklaamvideotele}

1. Kindlustusfirma Ergo inglireklaamid. (See reklaamiseeria oli Eesti reklaamikonkursi Kuldmuna 2009 üks võitjaid.)

Meessoost kaitseingel loeb WC-s ajalehte ja väidab, et tal pole aega hädasolijat kaitsma minna (http://www.youtube.com/watch?v=gMJXj_fbk8A).

Kaitseingel mängib piljardit ja väidab, et tal pole parasjagu tööaeg (http://www.youtube. $\mathrm{com} /$ watch? $\mathrm{v}=\mathrm{nEyoVC5F}$ cjs\&NR=1\&feature=endscreen).

Tänavatel autodevoolus sagiv kaitseingel ei jaksa enam (http://www.youtube.com/wat ch?v=dwdcgQdaau0\&feature=related).

Kaitseingel toriseb edasi-tagasi jooksutamise pärast (http://www.youtube.com/ watch?v=rG7lzMxFLmE).

2. Mercedes Benz'i reklaam. Lapsinglid lebavad laiseldes pilvevahus ja vestlevad (http:// www.myvideo.de/watch/5873154/Mercedes_Benz_Werbung_mit_Engel_WITZIG).

3. Angel Soft WC-paberi reklaam. Lõbusa välimusega meesinglid aitavad kiita WCpaberi pehmust (http://www.youtube.com/watch?v=6N_M8b1fXYQ\&feature=related).

4. Coca-Cola reklaam. Naisingel, kes joob kokakoolat, muutub neiuks ja leiab peiu (http://www.youtube.com/watch?v=1zB0J1IzfVo).

5. Volkswagen Polo autoreklaam. Kaitseinglid passivad kõikjal oma hoolealuseid, ainult Volkswagen Polo juhi kaitseingel uitab mujal ringi, kuna autosolija saab end 
tänu oma autole niisamagi turvaliselt tunda (http://www.youtube.com/watch?v=qf59 SbnKXM\&NR=1).

6. Lancia autoreklaam reklaamlausega "See pole kurjaingel, vaid armastus," näitab, kuidas musta riietatud mees suudleb musta riietatud inglit, kuni tollel tiivad seljast kukuvad (http://www.youtube.com/watch?v=-JN6Uu61WP8).

7. Lancia autoreklaam. Lancia uus mudel kihutab kadedatest meesinglitest mööda, nii et neil suled seljast langevad (http://www.youtube.com/watch?v=EVYMKQUiZ0k\&NR=1).

8. Lux seebireklaam. Lux seebiga pesev naisingel tantsib, kuni tiivad seljast kukuvad (http://www.youtube.com/watch?v=RvuN2n7WvWs\&NR=1).

9. Victoria's Secret pesureklaam. Sensuaalses pesus ingliparv, reklaamlause: "Tee oma inglile jõuludeks kingitus, mida sa kunagi ei unusta." (http://www.youtube.com/ watch?v=aMWZkIkkzbc).

10. Meesteparfüüm Lynx Excite. Suurlinna tänavatel jalutavad inglid, kes üksteise järel kukuvad, reklaamlause: "Isegi inglid langevad/kukuvad" (sõnademäng sõna "fall" (kukkuma, langema) baasil) (http://www.youtube.com/watch?v=riwBXClOSyo).

11. Kondenspiim Angel Milk. Rõõmsalt ringilendlev lapsingel reklaamib kondenspiima (http://www.youtube.com/watch?v=TJ8bF09TrM8).

12. Lay's kartulikrõpsud. Krõpse krõmpsutav kurat kiidab nende maitset (http://www. youtube.com/watch?v=klZErv_QHEg).

\section{Summary}

\section{From a heavenly guide to a messenger of the commercial world: Stereotypes of an angel in advertisements}

\section{Reet Hiiemäe}

Key words: angels, contemporary folklore, folk belief, mentality, values

This empirical research intends to analyse the use and functions of the image of an angel in advertisements. The aim of the article is to follow the modifications and adaptations that the image of an angel has gone through during centuries, and to find out whether the portraying of angels in advertisements would allow us to draw conclusions about people's contemporary beliefs and values in Estonia as well as elsewhere in the world. The analysis is based on about 50 advertisements that have mainly been produced during the last ten years. 